Proceedings of the International Conference On Ummah:

Digital Innovation, Humanities And Economy (ICU: DIHEc) 2020 https://doi.10.30874/ksshr.2

\title{
The Roles of Japanese Industrial Sectors: The Perspective of Input-Output Analysis
}

\author{
Ubaidillah Zuhdi ${ }^{1}$, Edza Aria Wikurendra ${ }^{2}$ \\ \{ubaidillah.zuhdi@unusa.ac.id ${ }^{1}$, edzaaria@unusa.ac.id ${ }^{2}$ \} \\ Universitas Nahdlatul Ulama Surabaya, Surabaya 60237, Indonesia ${ }^{1,2}$ \\ Gdansk University of Technology, Gdansk 80-233, Poland
}

\begin{abstract}
The purpose of this study is to analyze the roles of industries in the national economy of Japan. The study employs Input-Output (IO) analysis as an analyis tool. More specifically, this study uses the parts of IO analysis, namely simple output multiplier, simple household income multiplier, index of the power of dispersion, and index of the sensitivity of dispersion as analysis devices. The analysis period of this study is 2011-2015. The results show that the consistency of several industries in influencing the Japanese national economy on the analysis period could be seen from both multipliers. Besides, the characteristics of almost all Japanese industrial sectors on the period of analysis did not change.
\end{abstract}

Keywords: Roles, Industries, National economy, IO analysis

\section{Introduction}

Industrial sectors have contributed a lot to the national economy of many countries. The contributions can be seen not only in the developed countries, but also in the developing countries. It should be noted that the contribution portion of existing industrial sectors can be different for each country.

There are many previous studies discuss the contribution or role of the industrial sector in the economy. For example, service sector generates a direct and significant contribution to job creation and GDP, and provides critical inputs for the rest of the economy, thus having a significant impact on the overall investment condition, which is an essential factor of development and growth [1]. The sector is the biggest and fastest growing sector in the economy of the world, accounting the highest share in total output and employment in the most developed countries. According to [2], the contribution of the sector in total GDP is 47 percent in low income nations, 53 percent in middle income nations, and 73 percent in high income countries. Meanwhile, the contribution of the service (tertiary) sector to India's GDP is $59.29 \%$, higher than primary $(13.68 \%)$ and secondary sectors $(27.03 \%)$ [3]. On the other hand, until now, manufacturing sector has a role as an engine of growth [4].

Based on the aforesaid previous studies, the use of Input-Output (IO) analysis in analyzing the roles of industrial sectors in the national economy of a specific country has not been investigated. IO analysis is a tool in analyzing the linkages of industrial sectors in one or more countries. Therefore, the tool is a suitable tool in investigating the roles. The importance and originality of this study are that it explores the roles by using IO analysis which focusing on the Japan national economy. 


\section{Kresna Social Science and Humanities Research}

Proceedings of the International Conference On Ummah: Digital Innovation, Humanities And Economy (ICU: DIHEc) 2020 https://doi.10.30874/ksshr.2

The purpose of this study is to analyze the roles of industries in the national economy of Japan. The study employs IO analysis as an analyis tool. More specifically, this study uses the parts of IO analysis, namely simple output multiplier, simple household income multiplier, index of the power of dispersion, and index of the sensitivity of dispersion as analysis devices. The analysis period of this study is 2011-2015. The rest of this paper is explained as follows. Section 2 shows the methodology of the study. Section 3 describes the results of calculations. Besides, the discussions for the results can be seen on this section too. The next section, section 4 , explains the conclusions of the study, and suggested future researches.

\section{Methodology}

The methodology of this study is described as follows. The first step is to explain the data used. The study uses Japanese IO tables for 2011 and 2015 as data. Both tables consist of thirteen industrial sectors, and use the producer's price. The sources of the data are [5] and [6]. The next step is to show the Japanese industrial sectors used in this study. Table 1 explains the sectors.

Table 1. Japanese industrial sectors used in this study (Source: [7] with a slight modification).

\begin{tabular}{cl}
\hline Sector number & \multicolumn{1}{c}{ Sector name } \\
\hline 1 & Agriculture, forestry, and fishery \\
2 & Mining \\
3 & Manufacturing \\
4 & Construction \\
5 & Electricity, gas, and water supply \\
6 & Commerce \\
7 & Finance and insurance \\
8 & Real estate \\
9 & Transport and postal services \\
10 & Information and communications \\
11 & Public administration \\
12 & Services \\
13 & Activities not elsewhere classified \\
\hline
\end{tabular}

The third step is to conduct the calculations by using simple output multiplier, and simple household income multiplier. Reference [8] explains the equations of both multipliers as follows:

$$
\begin{gathered}
m(o)_{j}=\sum_{i=1}^{n} l_{i j} \\
m(h)_{j}=\sum_{i=1}^{n} a_{n+1, i} l_{i j} .
\end{gathered}
$$

The former model describes the simple output multiplier while the latter one explains the simple household income multiplier. More specifically, $m(o)_{j}, m(h)_{j}, a_{n+1, i}, n$, and $l_{i j}$ are simple output 


\section{Kresna Social Science and Humanities Research}

Proceedings of the International Conference On Ummah: Digital Innovation, Humanities And Economy (ICU: DIHEc) 2020 https://doi.10.30874/ksshr.2

multiplier for sector $j$, simple household income multiplier for sector $j$, labor-input coefficients, the number of analyzed sectors, and a sector-to-sector multipliers matrix, respectively.

The fourth step is to conduct the calculations in order to investigate the characteristics of Japanese industrial sectors on the analysis period. The methods used in the calculations are the (1) index of the power of dispersion, and (2) index of the sensitivity of dispersion. The former index is utilized to analyze the strength of one specific sector in influencing entire industries. A greater influence is aligned with the higher index value. The detail of the index is explained by [9] as follows:

$$
\text { Index of the power of dispersion by sector }=\frac{b_{* j}}{\bar{B}} \text {. }
$$

The numerator is each sum of column in the table of inverse matrix coefficients while the denominator explains the mean value of the entire vertical sum in the table of inverse matrix coefficients. More specifically, the equations of numerator and denominator are described as follows:

$$
\begin{gathered}
b_{*_{j}}=\sum_{i}^{n} b_{i j} \\
B=\frac{1}{n \sum_{j} b_{* j}=} \frac{1}{n} \sum_{i} \sum_{j} b_{i j} .
\end{gathered}
$$

Further, $b_{i j}$ and $n$ are the value of Leontief inverse from sector $i$ to sector $j$, and total number of analyzed industrial sectors, respectively.

The latter index is utilized to analyze the sensitivity of the specific sector to the external influences. A greater sensitivity is aligned with the greater index value. More specifically, one particular sector is called more sensitive to the influences from the external aspects if it has a higher index value. The detail of the index is explained by [9] as follows:

$$
\text { Index of the sensitivity of dispersion by sector }=\frac{b_{i^{*}}}{\bar{B}} \text {. }
$$

In this index, the numerator is each sum of row in the table of inverse matrix coefficients while the denominator describes the mean value of the entire horizontal sum in the table of inverse matrix coefficients. Further, the equations of the numerator and denominator of the index are explained as follows:

$$
b_{i^{*}}=\sum_{j}^{n} b_{i j}
$$




\section{Kresna Social Science and Humanities Research}

Proceedings of the International Conference On Ummah:

Digital Innovation, Humanities And Economy (ICU: DIHEc) 2020

https://doi.10.30874/ksshr.2

$$
B=\frac{1}{n_{i}} \sum_{i^{*}} b=\frac{1}{n_{i}} \sum_{j} b_{i j} .
$$

In order to get a compatibility sense with the previous index, equation (7) is slightly modified from the original source. More specifically, the part explains the total number of discussed industries, $n$, is added into the equation. As with the previous explanation, $b_{i j}$ is the Leontief inverse value from sector $i$ to sector $j$. The fifth step is to analyze the roles of Japanese industrial sectors in the national economy on the analysis period. Conclusions of the study, and suggested further researches are explained afterwards.

\section{Results and Analysis}

Table 2 describes the top five Japanese industrial sectors viewed from the values of simple output multiplier in 2011. Reference [8] describes that an output multiplier for sector $j$ is the total value of production in all industries of the economy that is needed in order to fulfill a currency's worth of final demand for the output of sector $j$. The reference also explains that, for the simple output multiplier, the total value of production is coming from the model of households exogenous.

Table 2. Top five Japanese industrial sectors viewed from the values of simple output multiplier, 2011 (Source: [10]).

\begin{tabular}{cclc}
\hline No. & Sector number & \multicolumn{1}{c}{ Sector name } & Simple output multiplier \\
\hline 1 & 3 & Manufacturing & 2.769 \\
2 & 5 & Electricity, gas, and water supply & 2.625 \\
3 & 4 & Construction & 2.268 \\
4 & 1 & Agriculture, forestry, and fishery & 2.210 \\
5 & 2 & Mining & 2.181 \\
\hline
\end{tabular}

Manufacturing sector, based on the information in the table, had the highest value in 2011. This result explains that in order to satisfy a yen's worth of final demand for manufacturing sector's output, all Japanese industries need to produce the products which the total value is $¥ 2.769$. By using the result, one can argue that an additional final demand for the sector would generate the most attractive effect to the economy of Japan in 2011.

On the other hand, table 3 shows the top five Japanese industrial sectors viewed from the values of simple output multiplier in 2015. Manufacturing sector, as with the previous result, had the highest value in 2015. Based on the information in the table, the value is 2.523. Although the value is smaller than the previous result, the fact explains the consistency of the sector in generating the attractive effect to the economy of Japan on the period of analysis through an additional final demand. One more thing, the compositions of top five sectors in tables 2 and 3 are similar. Based on this result, one can argue that several industries showed the consistency in influencing the Japanese national economy on the analysis period.

Figures 1 and 2 show the values of simple output multiplier of all Japanese industries in 2011 and 2015, respectively. The average values of simple output multiplier of Japanese industrial sectors in 2011 and 2015 were 2.029 and 1.905, respectively. This fact is interesting 


\section{Kresna Social Science and Humanities Research}

Proceedings of the International Conference On Ummah:

Digital Innovation, Humanities And Economy (ICU: DIHEc) 2020

https://doi.10.30874/ksshr.2

because it explains that Japan had a higher average value in 2011, the year when the natural disasters were happened.

Table 3. Top five Japanese industrial sectors viewed from the values of simple output multiplier, 2015.

\begin{tabular}{cclc}
\hline No. & Sector number & \multicolumn{1}{c}{ Sector name } & Simple output multiplier \\
\hline 1 & 3 & Manufacturing & 2.523 \\
2 & 5 & Electricity, gas, and water supply & 2.252 \\
3 & 4 & Construction & 2.157 \\
4 & 1 & Agriculture, forestry, and fishery & 2.150 \\
5 & 13 & Activities not elsewhere classified & 2.050 \\
\hline
\end{tabular}

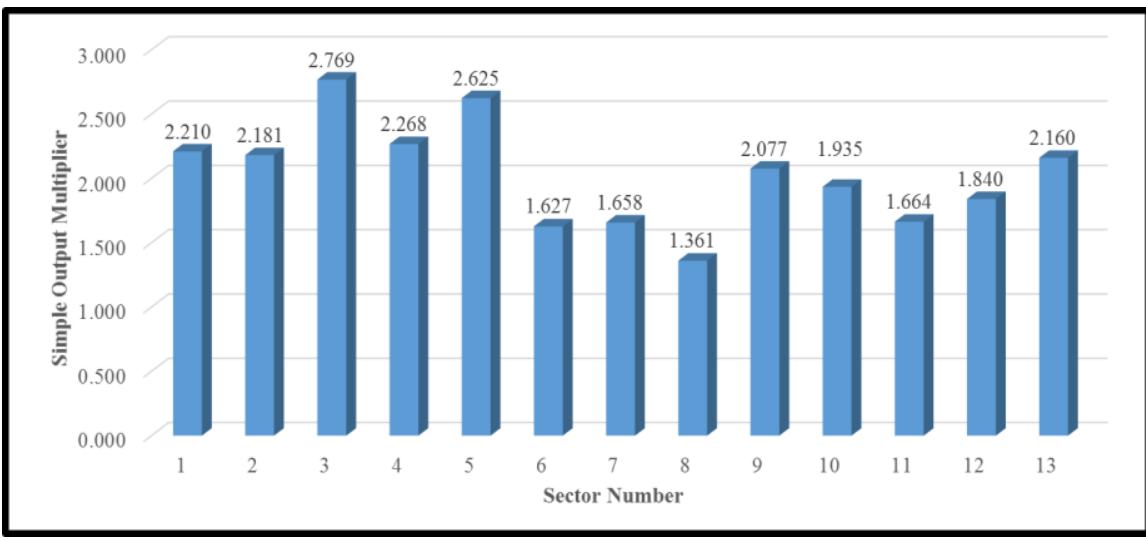

Fig. 1. The values of simple output multiplier of Japanese industrial sectors, 2011 (Source: [10]).

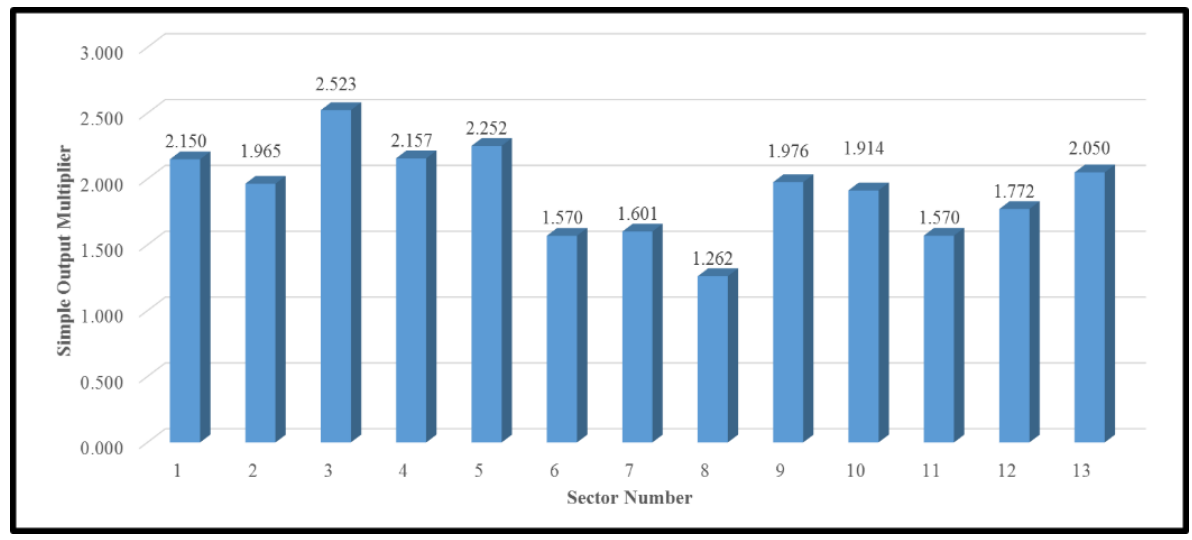

Fig. 2. The values of simple output multiplier of Japanese industrial sectors, 2015.

Table 4 shows the top five Japanese industrial sectors viewed from the values of simple household income multiplier in 2011. Reference [8] describes that the multiplier is applied to explain the economic impacts of new final demand as measured by new households income by 


\section{Kresna Social Science and Humanities Research}

Proceedings of the International Conference On Ummah: Digital Innovation, Humanities And Economy (ICU: DIHEc) 2020 https://doi.10.30874/ksshr.2

using the model of households exogenous. Based on the information in the table, the highest value was owned by the construction sector in 2011 .

Table 4. Top five Japanese industrial sectors viewed from the values of simple household income multiplier, 2011 (Source: [10]).

\begin{tabular}{cclc}
\hline No. & Sector number & \multicolumn{1}{c}{ Sector name } & Simple household income multiplier \\
\hline 1 & 4 & Construction & 0.646 \\
2 & 12 & Services & 0.618 \\
3 & 9 & Transport and postal services & 0.560 \\
4 & 6 & Commerce & 0.554 \\
5 & 11 & Public administration & 0.543 \\
\hline
\end{tabular}

Meanwhile, table 5 explains the top five Japanese industrial sectors viewed from the values of simple household income multiplier in 2015. As with the previous result, the highest value in the table is owned by the construction sector. In general, the composition of the top five sectors did not change from 2011 to 2015. In other words, the consistency of several industries in influencing the Japanese national economy on the analysis period could be seen from this multiplier. This fact is in line with the calculation results of previous multiplier.

Table 5. Top five Japanese industrial sectors viewed from the values of simple household income multiplier, 2015.

\begin{tabular}{cclc}
\hline No. & Sector number & \multicolumn{1}{c}{ Sector name } & Simple household income multiplier \\
\hline 1 & 4 & Construction & 0.606 \\
2 & 12 & Services & 0.588 \\
3 & 6 & Commerce & 0.531 \\
4 & 9 & Transport and postal services & 0.522 \\
5 & 11 & Public administration & 0.511 \\
\hline
\end{tabular}

Figures 3 and 4 show the values of simple household income multiplier of all Japanese industrial sectors in 2011 and 2015, respectively. The average values of simple household income multiplier of Japanese industrial sectors in 2011 and 2015 were 0.480 and 0.440 , respectively. This fact is in line with the phenomenon that can be seen in the previous multiplier. 


\section{Kresna Social Science and Humanities Research}

Proceedings of the International Conference On Ummah:

Digital Innovation, Humanities And Economy (ICU: DIHEc) 2020

https://doi.10.30874/ksshr.2

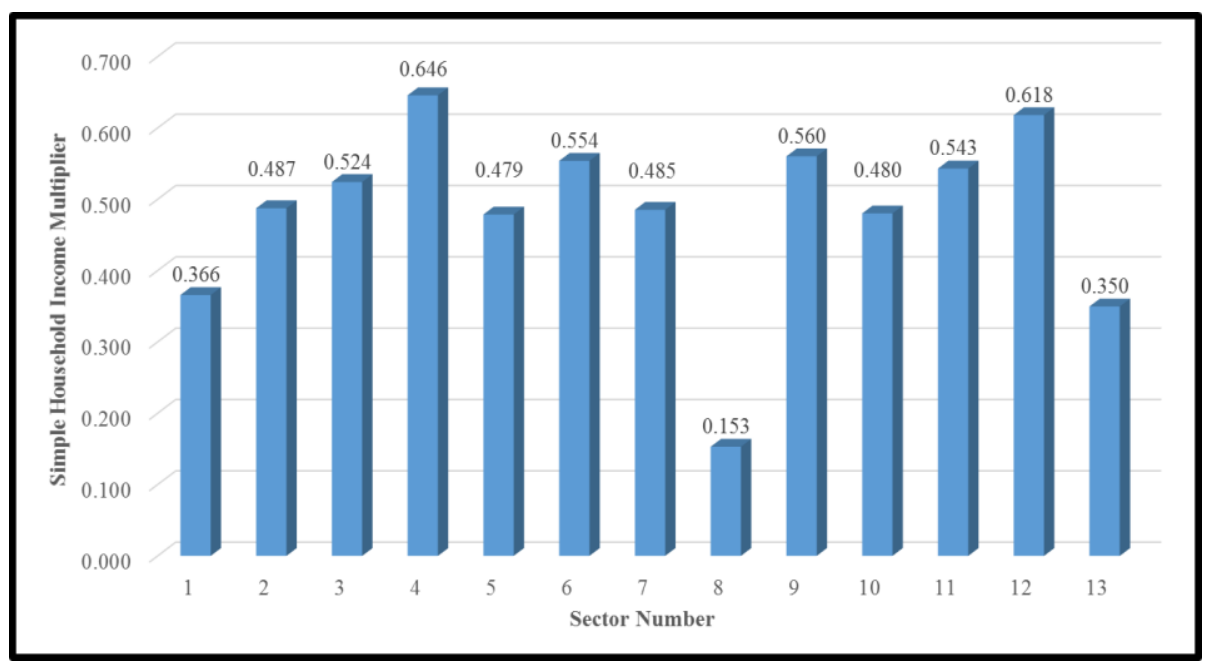

Fig. 3. The values of simple household income multiplier of Japanese industrial sectors, 2011 (Source: [10]).

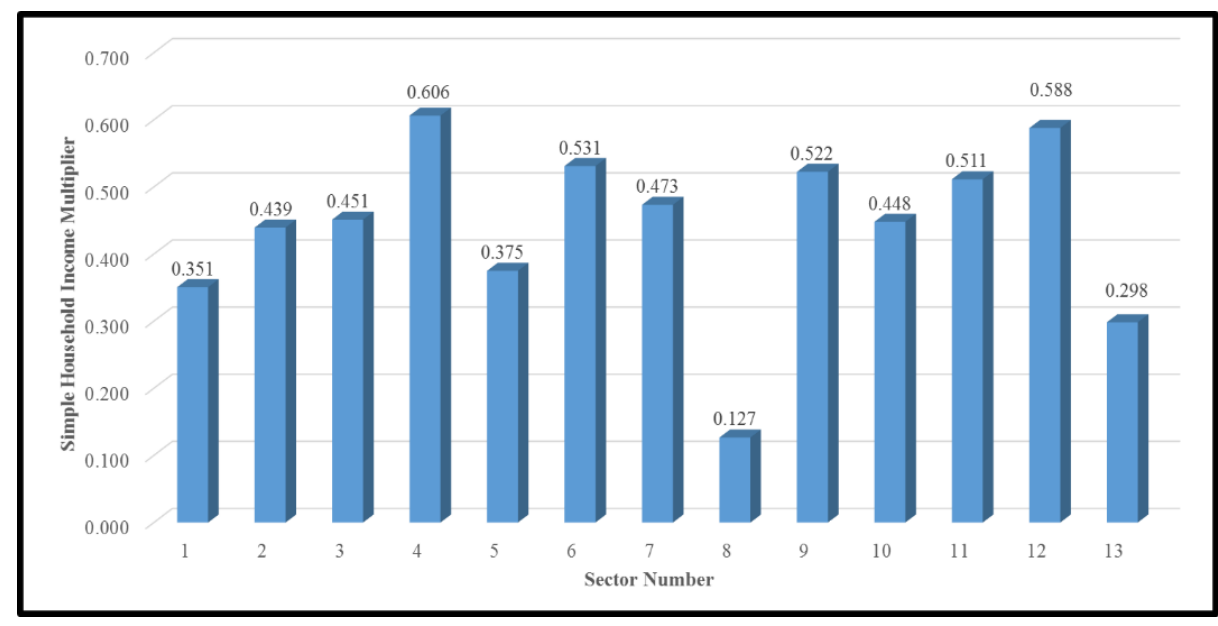

Fig. 4. The values of simple household income multiplier of Japanese industrial sectors, 2015.

Figures 5 and 6 plot the discussed sectors, and combine both indices used in this study in one chart for 2011 and 2015, respectively. More specifically, the horizontal axis of the chart explains the values of the index of the power of dispersion while the vertical axis places the values of another index. The chart has four quadrants. Each discussed sector has a specific quadrant in the chart.

Each quadrant has peculiar characteristics. More specifically, the quadrant I is a place where the values of both indices are more than one. In other words, the industries include on this quadrant are those most impacted by the external aspects as well as have strong influences on the entire industries. The opposite phenomena can be seen on the sectors which include on the quadrant III. On the other hand, quadrant II is a place where the value of the index of the 


\section{Kresna Social Science and Humanities Research}

Proceedings of the International Conference On Ummah: Digital Innovation, Humanities And Economy (ICU: DIHEc) 2020 https://doi.10.30874/ksshr.2

power of dispersion is less than one while the value of another index is more than one. One can argue that the industries include on this quadrant are those which have weak influences on the entire industries, but they get high impacts from the changes of external aspects. The opposite characteristics are owned by the industries which include on the quadrant IV.

Based on the information in both figures, sectors 3 and 9 placed the quadrant I on the period of analysis. These sectors are manufacturing, and transport and postal services, respectively. The fact shows that, from 2011 through 2015, both industries had strong influences on the Japanese economic activities, and received great effects from the external aspects. Therefore, the Japanese government should prioritize the industries developments on the future.

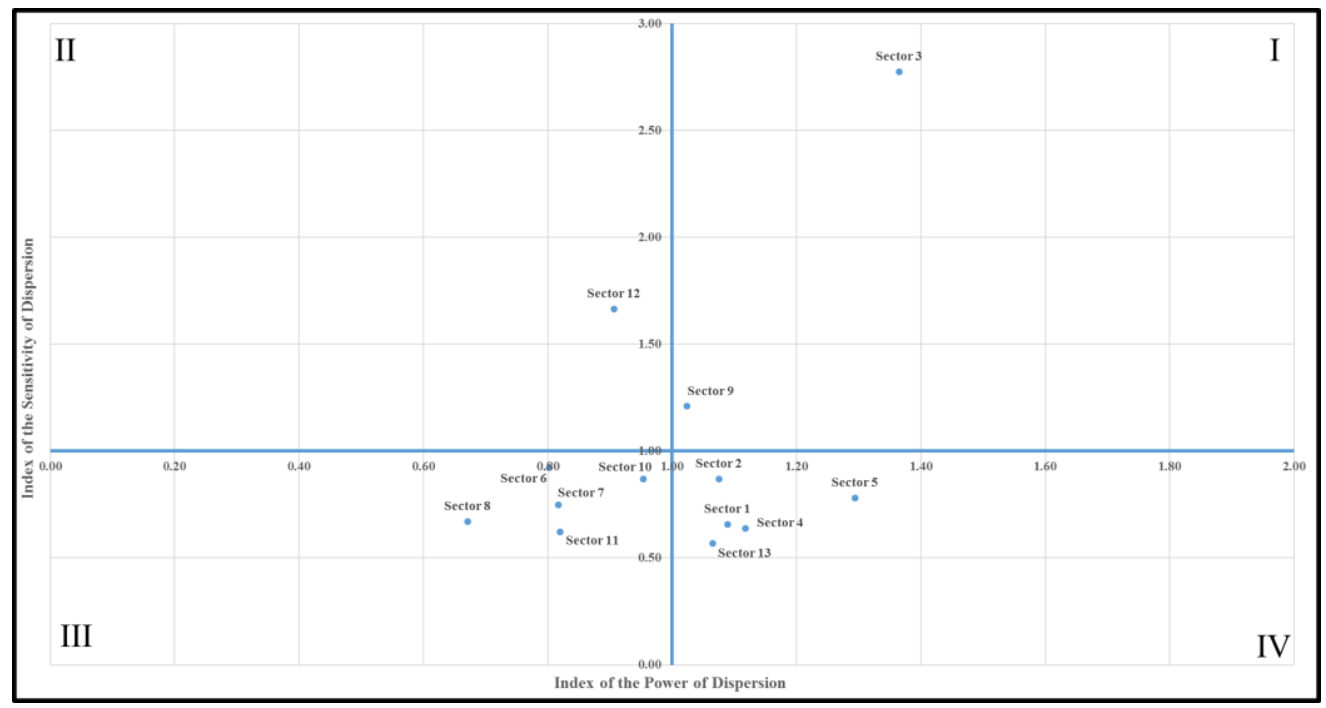

Fig. 5. The quadrants for Japanese industrial sectors based on the indices of the power of dispersion, and the sensitivity of dispersion, 2011 (Source: [7]). 


\section{Kresna Social Science and Humanities Research}

Proceedings of the International Conference On Ummah: Digital Innovation, Humanities And Economy (ICU: DIHEc) 2020 https://doi.10.30874/ksshr.2

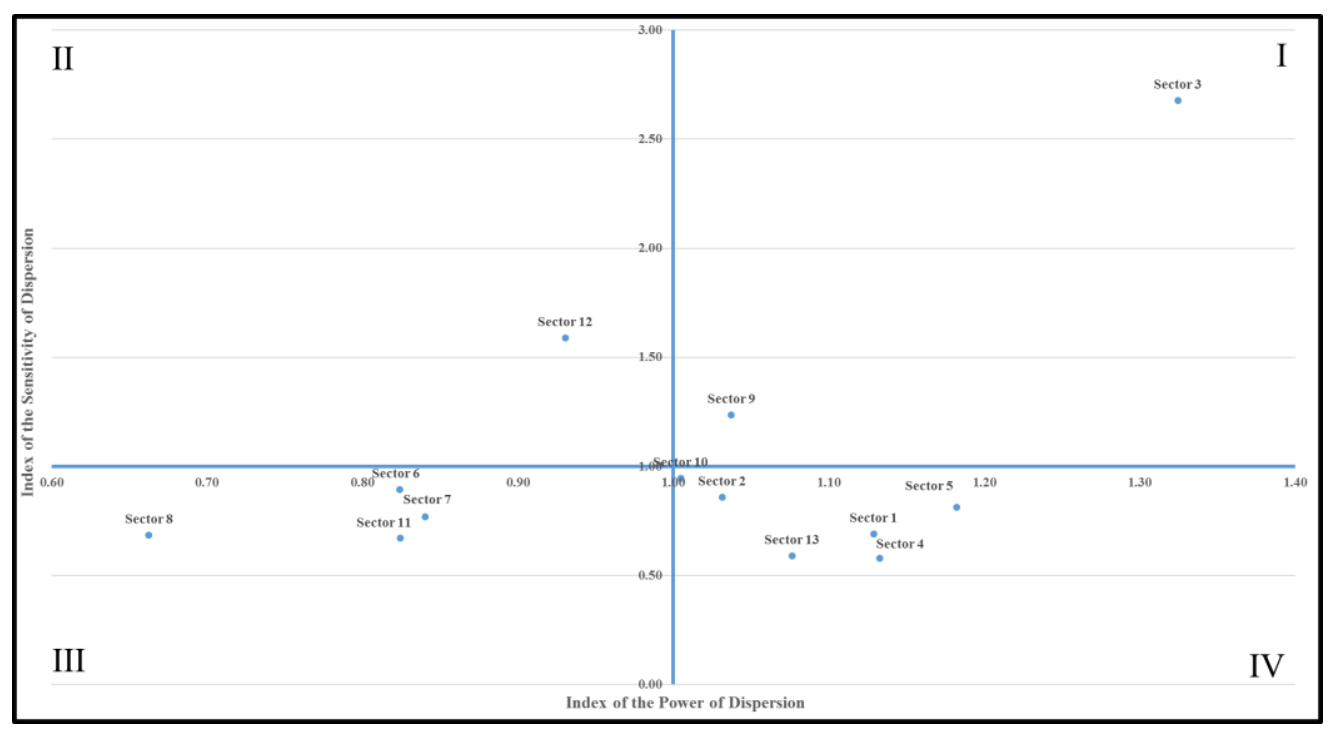

Fig. 6. The quadrants for Japanese industrial sectors based on the indices of the power of dispersion, and the sensitivity of dispersion, 2015.

Tables 6 and 7 summarize the quadrants of analyzed industries in 2011 and 2015, respectively. Based on the information in these tables, one can argue that, from 2011 through 2015, almost all Japanese industries were on the same quadrant. The movement on the period of analysis was owned by the sector 10, information and communications. More specifically, on the analysis period, the movement of the sector was happened from quadrant III to quadrant IV. The fact shows that the characteristics of almost all Japanese industrial sectors on the period of analysis did not change. This is an interesting fact, especially because the natural disasters were happened in Japan in 2011.

Table 6. The quadrants of Japanese industrial sectors, 2011 (Source: [7]).

\begin{tabular}{clc}
\hline Sector number & \multicolumn{1}{c}{ Sector name } & Quadrant \\
\hline 1 & Agriculture, forestry, and fishery & IV \\
2 & Mining & IV \\
3 & Manufacturing & I \\
4 & Construction & IV \\
5 & Electricity, gas, and water supply & IV \\
6 & Commerce & III \\
7 & Finance and insurance & III \\
8 & Real estate & III \\
9 & Transport and postal services & I \\
10 & Information and communications & III \\
11 & Public administration & III \\
12 & Services & II \\
13 & Activities not elsewhere classified & IV \\
\hline
\end{tabular}




\section{Kresna Social Science and Humanities Research}

Proceedings of the International Conference On Ummah: Digital Innovation, Humanities And Economy (ICU: DIHEc) 2020 https://doi.10.30874/ksshr.2

Table 7. The quadrants of Japanese industrial sectors, 2015.

\begin{tabular}{clc}
\hline Sector number & \multicolumn{1}{c}{ Sector name } & Quadrant \\
\hline 1 & Agriculture, forestry, and fishery & IV \\
2 & Mining & IV \\
3 & Manufacturing & I \\
4 & Construction & IV \\
5 & Electricity, gas, and water supply & IV \\
6 & Commerce & III \\
7 & Finance and insurance & III \\
8 & Real estate & III \\
9 & Transport and postal services & I \\
10 & Information and communications & IV \\
11 & Public administration & III \\
12 & Services & II \\
13 & Activities not elsewhere classified & IV \\
\hline
\end{tabular}

\section{Conclusions and Further Researches}

This study analyzes the roles of Japanese industrial sectors in the Japanese national economy by using IO analysis. More specifically, this study uses simple output multiplier, simple household income multiplier, index of the power of dispersion, and index of the sensitivity of dispersion as analysis tools. The analysis period of this study is 2011-2015.

The results show that the consistency of several industries in influencing the Japanese national economy on the analysis period could be seen from both multipliers. Besides, the characteristics of almost all Japanese industrial sectors on the period of analysis did not change. These are interesting facts especially because the natural disasters were happened in Japan in 2011.

The understanding regarding the roles of Japanese industrial sectors in influencing the Japanese national economy on the analysis period is obtained from the current study. However, the study uses the aggregated industries. In other words, the study is still far from describing the whole view about the roles. The view is needed in order to know better the situations of Japanese national economy so the comprehensive policies for improving those in the future can be made. Therefore, as a further research, the study proposes the same analysis for the disaggregated Japanese industrial sectors.

The other suggested further research from the study is to conduct an international comparison using the same analysis. The comparison can be done among developed as well as developed-developing countries. The comparison might explore the roles of the industries of compared countries so the similarities and differences among those can be analyzed. One of the examples of the comparison is Japan and Indonesia. 


\section{Kresna Social Science and Humanities Research}

Proceedings of the International Conference On Ummah: Digital Innovation, Humanities And Economy (ICU: DIHEc) 2020 https://doi.10.30874/ksshr.2

\section{References}

[1] The Organisation for Economic Co-operation and Development. The contribution of services to development and the role of trade liberalisation and regulation. 2008; https://www.oecd.org/investment/globalforum/40302909.pdf (accessed September 18, 2020).

[2] Ahmed, A., Ahsan, H. Contribution of services sector in the economy of Pakistan. 2011; https://www.pide.org.pk/pdf/Working\%20Paper/WorkingPaper-79.pdf (accessed September 18, 2020).

[3] Singh, R. S. India's service sector-shaping future of Indian retail industry. Proc. econ fin. 2014; 11: 314-322.

[4] Szirmai, A. Industrialisation as an engine of growth in developing countries, 1950-2005. Struct change econ dyn. 2012; 23 (4): 406-420.

[5] Ministry of Internal Affairs and Communications Japan. 2011 Input-output tables for Japan. 2016; https://www.soumu.go.jp/main_content/000443188.pdf (accessed September 11, 2020).

[6] Ministry of Internal Affairs and Communications Japan. 2015 Input-output table: transaction basic table (producer's price) (13 sectors) (Japanese). 2019; https://www.e-stat.go.jp/stat-search/filedownload?statInfId=000031839449\&fileKind $=0$ (accessed September 11, 2020).

[7] Zuhdi, U. An analysis of the characteristics of Japanese industrial sectors from 2005 through 2011. IOP conf. ser.: earth environ. sci. 2017; 88 (012027): 1-7.

[8] Miller, R. U., Blair, P. D. Input-output analysis: foundations and extensions. Second edition. New York: Cambridge university press; 2009. 250-252.

[9] Ministry of Internal Affairs and Communications Japan. Chapter IV: coefficients for input-output analysis and computation methods. n.d.; https://www.soumu.go.jp/main_content/000327480.pdf (accessed September 13, 2020).

[10] Zuhdi, U., Herlambang, T., Nasori, N. Using multiplier analyses in analyzing the roles of Japanese industrial sectors. IJEAT. 2019; 8 (5C): 229-232. 